\title{
Respiratory Failure, CTCAE
}

National Cancer Institute

\section{Source}

National Cancer Institute. Respiratory Failure, CT CAE. NCI Thesaurus. Code C143809.

A disorder characterized by impaired gas exchange by the respiratory system resulting in hypoxia and a decrease in oxygenation of the tissues that may be associated with an increase in arterial levels of carbon dioxide. 